This document is confidential and is proprietary to the American Chemical Society and its authors. Do not copy or disclose without written permission. If you have received this item in error, notify the sender and delete all copies.

\title{
Ethanol Controls the Self-Assembly and Mesoscopic Properties of Amyloid Spherulites
}

\begin{tabular}{|r|l|}
\hline Journal: & The Journal of Physical Chemistry \\
\hline Manuscript ID & jp-2018-01779n \\
\hline Manuscript Type: & Article \\
\hline Date Submitted by the Author: & 21 -Feb-2018 \\
\hline Complete List of Authors: & $\begin{array}{l}\text { Vetri, Valeria; Università di Palermo, Dipartimento di Fisica e Chimica } \\
\text { Piccirilli, Federica; Università di Palermo, Physics Department } \\
\text { Krausser, Johanne; University of Cambridge } \\
\text { Buscarino, Gianpiero; Università di Palermo, Dipartimento di Fisica e } \\
\text { Chimica } \\
\text { Łapińska, Urszula; University of Cambridge Department of Chemistry } \\
\text { Vestergaard, Bente; University of Copenhagen, Drug Design and } \\
\text { Pharmacology } \\
\text { Zaccone, Alessio; University of Cambridge, Cavendish Laboratory } \\
\text { Foderà, Vito; University of Copenhagen, Pharmacy }\end{array}$ \\
\hline
\end{tabular}

\section{SCHOLARONE ${ }^{\mathrm{m}}$}

Manuscripts 


\title{
Ethanol Controls the Self-Assembly and Mesoscopic Properties of Amyloid Spherulites
}

\author{
Valeria Vetri,,$^{\dagger}$ Federica Piccirilli, ${ }^{\dagger}$ Johannes Krausser,,$^{*}$ Gianpiero Buscarino,,$^{\dagger}$ Urszula \\ Eapińska, ${ }^{\S}$ Bente Vestergaard, ${ }^{\pi}$ Alessio Zaccone, ${ }^{*}$ and Vito Foderà, $,{ }^{\pi}, \#, *$ \\ ${ }^{\dagger}$ Dipartimento di Fisica e Chimica and Advanced Technologies Network Center (ATEN) \\ Università degli Studi di Palermo, Viale delle Scienze ed.18, 90128, Palermo, Italy. \\ Department of Chemical Engineering and Biotechnology, University of Cambridge, Pembroke \\ Street Cambridge CB2 3RA, United Kingdom. \\ $\S$ Department of Chemistry, University of Cambridge, Lensfield Road, Cambridge CB2 1EW \\ United Kingdom. \\ "Department of Drug Design and Pharmacology, University of Copenhagen, Universitetsparken \\ 2, 2100 Copenhagen, Denmark. \\ \# Section for Biologics, Department of Pharmacy, University of Copenhagen, Universitetsparken \\ 2, 2100 Copenhagen, Denmark.
}

KEYWORDS Amyloid-like Spherulites; Hydration; Fluorescence; High Pressure Spectroscopy; Theory of self-assembly 


\begin{abstract}
Protein self-assembly into amyloid fibrils or highly hierarchical superstructures is closely linked to neurodegenerative pathologies as Alzheimer's and Parkinson's diseases. Moreover, protein assemblies also emerged as building blocks for bio-inspired nanostructured materials. In both the above mentioned fields the main challenge is to control the growth and properties of the final protein structure. This relies on a more fundamental understanding of how interactions between proteins can determine structures and functions of biomolecular aggregates. Here we identify a striking effect of the hydration of the single protein molecule and solvent properties in controlling hydrophobicity/hydrophilicity, structures and morphologies of a superstructure named spherulite, observed in connection to Alzheimer's disease. Depending on the presence of ethanol, such structures can incorporate fluorescent molecules with different physico-chemical features, and span a range of mechanical properties and morphologies. A theoretical model providing a thorough comprehension of the experimental data is developed, highlighting a direct connection between the intimate physical protein-protein interactions, the growth and the properties of the self-assembled superstructures. Our findings indicate structural variability as a general property for amyloid-like aggregates and not limited to fibrils. This knowledge is pivotal not only for developing effective strategies against pathological amyloids but provides also a platform for designing highly tunable biomaterials, alternative to elongated protein fibrils.
\end{abstract}

KEYWORDS: amyloid-like spherulites; hydration; amyloid polymorphism; self-assembled biomaterials; neurodegenerative diseases; high-pressure spectroscopy; theory of self-assembly 


\section{INTRODUCTION}

Undergoing a self-assembly reaction is a possible and general pathway for several proteins and peptides. ${ }^{1}$ A class of degenerative pathologies as Parkinson's and Alzheimer's diseases are associated with protein self-assembly ${ }^{1}$ and specifically with the formation of elongated aggregates known as amyloid fibrils. ${ }^{2}$ Fibrils have a width of 2-10 nm and length up to hundreds $\mu \mathrm{m}$ and, due to their architecture, they are resistant against chemical destabilization. ${ }^{3}$ This leads them to accumulate in the diseased tissues, but it is still debated whether fibrils are a cause or a by-product in the disease progression. ${ }^{4}$

Protein aggregation is not only associated to neurodegenerative diseases. In the last decade, amyloid-like fibrils attracted an extraordinary interest as potential nature-inspired biomaterials. $^{5-7}$ They are highly ordered, and their exceptional strength, elasticity and biocompatibility make them unique in the broad landscape of available biomolecules. However, their peculiar 2D geometry may limit the range of possible applications. ${ }^{6-10}$ Indeed, effective biomaterials should be highly tunable and contain molecular building blocks that undergo molecular level changes, which result in altered non-covalent interactions. These, in turn, translate into various mesoscopic responses. Tissue engineering, regenerative medicine and biosensing are a few examples in which the possibility to rationally design "easily tunable" materials would increase the rate of success for their application. ${ }^{11}$

Either one looks at protein aggregation in the context of diseases or biomaterials, the main aim is to control the aggregation process. Controlling the protein aggregate growth means to quantitatively unraveling the physical interactions that govern the self-assembly. ${ }^{12}$ These determine indeed the physical properties of the aggregate as well as their biological effect in 
diseases. $^{13-14}$ Subtle changes in the protein-protein interactions (PPIs, e.g. electrostatics, hydration forces, hydrophobic interactions) do also generate different structures. This is not only related to the formation of structurally and morphologically different fibrils (commonly known as fibril polymorphism). ${ }^{13-16}$ Indeed, the occurrence of another form of amyloid-like protein aggregates, named spherulites, has been increasingly reported in the last years. ${ }^{12}$ Spherulites are spherical $\mu \mathrm{m}$-structures formed by a dense core from which a low density corona develops. ${ }^{17}$ They can be obtained in vitro under specific conditions and from a wide range of structurally different proteins ${ }^{12,17-19}$ and can either coexist with fibrils or be the sole result of the aggregation process. ${ }^{20}$ Spherulites are now recognized as not being a minor component within a protein aggregation reaction $^{20}$ and they are also reported in connection with Alzheimer's disease. ${ }^{21,22}$ The occurrence of this alternative structure appears to be regulated by electrostatics interactions. $^{17,20}$

The above facts change the paradigm that associates amyloid-like aggregation uniquely to the formation of elongated fibrils and pose new questions on the role of different PPIs in determining specific amyloid structures, being this knowledge pivotal for the disease's etiology. ${ }^{23}$ Moreover, the existence of a wider range of structures other than fibrils offers a novel, yet poorly explored, platform for the development of new biomaterials.

Understanding the connection between specific PPIs and the biological and structural heterogeneity of the final aggregated species remains still elusive. ${ }^{24}$ Protein charge ${ }^{25}$ and hydrophobic interactions ${ }^{26}$ are indicated as main drivers for the conformational switch in fibril structures. Electrostatics also determines the self-assembly into superstructures, such as spherulites and particulates. ${ }^{27}$ In vitro and in vivo these interactions are mediated by the solvent composition and the cellular environment, respectively. In both cases, water molecules interact 
with the exposed protein residues. This leads to the formation of a hydration layer, which has marked differences compared to pure bulk water and whose dynamics plays a fundamental role in protein function. The hydration layer regulates hydrophobic attractions and the structural properties of proteins in aqueous environment. ${ }^{28}$ As a consequence, hydration water molecules (and hydration forces) are key players in protein folding. ${ }^{28,}{ }^{29}$ Short and long range hydration forces arising from both entropic and enthalpic contributions can also determine the protein selfassembly into amyloid structures,${ }^{30}$ but very little is known on how they specifically affect the kinetics of formation and morphologies of the final aggregates. Recent studies reveal the role of water molecules and hydration on the growth of amyloid fibrils ${ }^{31}$ and on the occurrence of conformational transitions within a fibril. ${ }^{32}$ Furthermore, an increased mobility of hydration water is reported for tau amyloid-like fibrils compared to native tau protein. ${ }^{33}$ While these studies give valuable insights on how fibrils and the related structural polymorphism depends on hydration, there is still a lack of knowledge on how hydration determines properties and growth of high hierarchical species as spherulites. The latter prevents the community from deciphering the physical general principles governing protein self-assembly in a more broad perspective, not limited to elongated fibrils.

Here we use ethanol (EtOH) to modify the hydration shell of a single human insulin molecule. Alcohols affect indeed protein hydration shell in a concentration-dependent manner ${ }^{34-}$ ${ }^{38}$ as well as the medium dielectric constant. ${ }^{39}$ As a main effect, alcohols modify the average macroscopic interaction between single molecules and, as a consequence, their interaction potentials. ${ }^{35}$ This is specifically reported for insulin ${ }^{36}$ and widely documented for different proteins. ${ }^{40-42}$ We show that changing the hydration shell and solvent properties leads to significant changes not only in the protein conformation and self-assembly kinetics of amyloid- 
like spherulites but also in their macroscopic features. We specifically observe a well-defined switching of the spherulite structural, mechanical and physico-chemical properties upon addition of EtOH while inducing the aggregate growth. Our data reveals how changes in the protein hydration water and solvent properties determine a pronounced polymorphism also in mesoscopic structures as spherulites, proving that structural variability is not only related to fibrils. Furthermore, our experimental and theoretical framework offers the possibility to univocally connect basic inter-protein physical interactions to the growth of the aggregates and the properties of the final structures. Due to the striking effects observed, our findings also promote spherulites as a natural platform for a broader development of highly-tunable protein biomaterials.

\section{MATERIALS AND METHODS}

Sample preparation. Human Insulin (HI) was obtained as a lyophilized powder from Sigma Aldrich (91077C). Solutions at protein concentration of $5 \mathrm{mg} / \mathrm{ml}$ were prepared dissolving the powder in water or water-ethanol mixtures with $0.25 \mathrm{M} \mathrm{NaCl}$ and aliquots of $10 \% \mathrm{v} / \mathrm{v} \mathrm{HCl}$ were added to the solutions to reach $\mathrm{pH} 1.8$. Samples were filtered through $0.22 \mu \mathrm{m}$ filters (MS 16534, Sartorius). Aggregation was thermally induced at $60^{\circ} \mathrm{C}$. Protein concentration was determined by UV absorbance at $276 \mathrm{~nm}$ using an extinction coefficient of 1.0 for $1.0 \mathrm{mg} / \mathrm{mL}$. Over the multiple sample preparations for different experiments we estimate an error of $\sim 12 \%$ on the protein concentration value. After the aggregation process, analysis of the residual native protein in the two samples shows that an almost complete conversion into spherulites is observed at $0 \%$ EtOH, while approximately $70 \%$ of the protein remains in the native state after $24 \mathrm{~h}$ incubation at $60^{\circ} \mathrm{C}$ in presence of $40 \% \mathrm{EtOH}$. 
Thioflavin T (ThT) fluorescence kinetics. For in situ ThT fluorescence, experiments were carried out using a plate reader system (Polarstar, BMG Labtech) with 96-microwell polystyrene plates (Nalge Nunc) with $200 \mathrm{ml}$ of solution per well and four replicates per sample. The plates were covered with non-sterile Polyolefin sealing tape (Nalge Nunc) to avoid evaporation of the sample and incubated at $60{ }^{\circ} \mathrm{C}$ without mechanical shaking. A stock solution of ThT in Milli-Q water $(1 \mathrm{mM})$ was prepared and stored a $4{ }^{\circ} \mathrm{C}$ protected from light to avoid photobleaching. ThT at the desired concentration $(20 \mu \mathrm{M})$ was added to each well prior to incubating the plate and the emission intensity at $480 \mathrm{~nm}$ was recorded upon excitation at $450 \mathrm{~nm}$. The emission signal was detected from the bottom of the plate every $400 \mathrm{~s}$ by an optical fibre system (bottom-bottom configuration).

2-photon excitation and confocal microscopy. Spherulites samples were diluted 1:10 and stained with ANS or ThT. $500 \mu$ aliquots of stained samples were placed on microscope chambered slides and imaged at 1024x1024 pixel resolution using a Leica RCS SP5 confocal laser scanning microscope using a $63 x$ or 40x objective (Leica Microsystems, Germany). Images obtained using ThT staining were acquired under excitation at 458nm in the emission range 470$550 \mathrm{~nm}$. ANS fluorescence was acquired using under two photon excitation at $780 \mathrm{~nm}$ using a Spectra-Physics Mai-Tai Ti:Sa ultra-fast laser. Alexa 647 fluorescence (red channel) was acquired in confocal configuration using the $633 \mathrm{~nm}$ visible laser as excitation source in the range of $650-710 \mathrm{~nm}$. For the presented Alexa 647 uptake experiments, the dye was added at 30 $\mu \mathrm{M}$ final concentration, and measurements were acquired after 12 hours. Multiple measurements were performed at different Alexa concentrations $(10 \mu \mathrm{M}$ to $70 \mu \mathrm{M})$ and uptake was measured as a function of time giving analogous results. Differences in staining between the two samples are independent of aggregate sizes and are also observed if samples are dialyzed against water (not 
shown). This evidence rules out any possible solvent effect on the dye diffusion/staining. The use of the mentioned dyes is due to their well-documented physico-chemical properties. ${ }^{43-46}$

Cross-polarized optical microscopy. Small aliquots of aggregated protein solutions (approximately $10 \mu \mathrm{L}$ ) were deposited onto a glass microscope slide. The images were collected using crossed polarisers, which enabled spherulites to be easily distinguished from the background by the characteristic Maltese cross optical microscope (Axioplan, Zeiss) without coverslips and at magnifications of up to $\times 20$. The polarizer and analyzer were in a fixed position (east-west and north-south on the images). Digital images were taken, and the scale was determined by taking images of a calibration slide with the same settings on the microscope.

Transmission Electron Microscopy (TEM). The imaging was performed on a Philips CM 100 Transmission Electron Microscope using a standard protocol. After 24 hours of fibrillation assay, performed as described above, the samples were diluted 50 -fold and $3.5 \mu 1$ aliquots were placed on Copper 400 mesh grids (Agar Scientific, Stansted, UK) coated with Formvar and carbon film. The grid was left for 60 seconds after which $10 \mu \mathrm{l}$ of distilled water was added and the excess water was removed. Then, $10 \mu 1$ of $2 \%$ uranyl acetate (Agar Scientific) was added and the grid left for 30 seconds. Finally, two $10 \mu \mathrm{l}$ drops of distilled water were placed on the grid, the excess water was removed and the grid was left to dry. ${ }^{20}$ Experiments were performed in triplicates.

High Pressure FTIR. In order to avoid sample signals overlapping with $\mathrm{OH}$ vibrational modes of water, deuterated samples were prepared as follow. Aggregates grown in EtOH-free and in $40 \% \mathrm{EtOH}(\mathrm{v} / \mathrm{v})$ buffer were pelleted by centrifugation (16162 g for 40 minutes) and resuspended in $20 \mu \mathrm{l}$ of $\mathrm{D}_{2} \mathrm{O}$. This procedure was repeated 3 times for each sample. After this treatment, confocal microscopy showed that spherulites were present in the samples with no 
detectable changes if compared to data in Figure 1. Deuterated solutions were placed into a membrane diamond anvil cell (DAC) equipped with IIa diamonds with a culet of $600 \mu \mathrm{m}$. A stainless steel gasket $40 \mu \mathrm{m}$ thick was used. A gas system was used to increase pressure. Pressure calibration was achieved through ruby fluorescence technique. ${ }^{47}$ Measurements were performed at SMIS beamline of SOLEIL synchrotron in Paris (http://www.synchrotronsoleil.fr/Recherche/LignesLumiere/SMIS), able to work in the energy range $100-4000 \mathrm{~cm}^{-1}$. IR transmission were measured with the use of a IR microscope coupled to a Fourier transform IR spectrometer and a nitrogen cooled MCT (Mercury Cadmium Telluride) detector, under continuum purging in $\mathrm{N}_{2}$ dry atmosphere. In order to collect the signal coming from single aggregates, the beam size was fixed to the size of each aggregate (about $10 \times 10 \mu \mathrm{m}^{2}$ for 40 -EtOH and $40 \mathrm{x} 40 \mu \mathrm{m}^{2}$ for 0 -EtOH). Samples in the DAC were illuminated with synchrotron light and the transmitted light in the region $700-4000 \mathrm{~cm}^{-1}$ was collected at the resolution of $1 \mathrm{~cm}^{-1}$ by accumulating 128 scans. Background spectra used to calculate samples absorbance were measured on sample surfaces free from aggregates. For constant pressure experiments, samples were compressed progressively to 4, 7 and $12 \mathrm{kbar}$ and measurements started after 10 minutes from each pressure increase after focus readjustment. The pressure jump experiment was achieved using the following protocol: samples were compressed to $12 \mathrm{kbar}$, kept at constant pressure for 20 minutes then decompressed to 1 bar with a decompression rate of $0.1 \mathrm{kbar} / \mathrm{s}$. The relaxation of the system was thus followed by measuring continuously the IR absorption (2 minutes for each measurement) until equilibrium was reached (after 12 minutes from pressure jump). Data analysis was performed using the software Opus Pro 7.5 (Bruker). Spectra were selected in the region of Amide I' band and baseline-corrected. A smoothing algoritm (13-points Savitzky-Golay) was applied to kinetic spectra. The secondary structure variation at the highest 
pressure was evaluated as the ratio between the area of the Amide I' band in the region 1610 $1630 \mathrm{~cm}^{-1}$ at $12 \mathrm{kbar}$ at 1 bar. $2^{\text {nd }}$-derivative technique was used for evaluating the spectral position of Tyrosine ring breathing mode in the region around $1515 \mathrm{~cm}^{-1}$. From the observation of $2^{\text {nd }}$-derivative minima it is possible to enhance the spectral resolution by resolving overlapping peaks. Tyrosine $2^{\text {nd }}$-derivative spectra was calculated using a 13 -points smoothing filter to absorption spectra.

Atomic Force Microscopy. Measurements were acquired in air by using a Bruker FAST-SCAN microscope equipped with a closed-loop scanner $(\mathrm{X}, \mathrm{Y}, \mathrm{Z}$ maximum scan ranges: $35 \mu \mathrm{m}, 35 \mu \mathrm{m}$, $3 \mu \mathrm{m}$, respectively). The scans were obtained in: (i) soft tapping mode, by using Bruker FASTSCAN-A ${ }^{\odot}$ probes with apical radius of about $5 \mathrm{~nm}$ and in (ii) PeakForce Tapping ${ }^{\odot}$ mode, by using Bruker SCANASYST-AIR ${ }^{\odot}$ probes with apical radius of about $3 \mathrm{~nm}$. Each AFM image was obtained with a pixel resolution comparable to the tip size.

Mechanical characterization of the materials were obtained by acquiring force-distance curves by using Bruker RTESPA (C) probes, characterized by a rotated piramidal tip with radius of about 5 nm. These data were analized by using the Hertz model to estimate the Young modulus of the materials. The analysis was performed on ten different spherulites showing that the Young modulus is systematically higher than $2 \mathrm{GPa}$ for $0 \% \mathrm{EtOH}$ and of about $400 \mathrm{MPa}$ for $40 \% \mathrm{EtOH}$. The uncertainty in the latter estimation is about $+/-100 \mathrm{MPa}$, essentially related to the inherent heterogeneity of the system. The estimation for the sample at $0 \% \mathrm{EtOH}$ has provided just a lower limit because the probe we used (Bruker RTESPA) was found to be unable to induce a measurable deformation of the surface in proximity of the tip apex, indicating that the surface is "harder" than the cantilever. Since it is well known that the probe we used is able to induce local 
deformations in samples with Young modulus up to $2 \mathrm{GPa}$, it was straightforward for us to conclude that the sample $0 \% \mathrm{EtOH}$ has actually a modulus larger than this value.

\begin{abstract}
Small Angle X-ray Scattering measurements and analysis. SAXS experiments were performed at bioSAXS beamline on BM29 (https://embl.fr/services/synchrotron_access/bm29/) at the ESRF (Grenoble, France). Samples were measured in the concentration range of 2-8 $\mathrm{mg} / \mathrm{ml}$ at a temperature of $10{ }^{\circ} \mathrm{C}$. Total sample exposure was $2 \mathrm{~min}$. Buffers were measured before and after sample exposure, and averaged before background subtraction. Repeated exposure did not reveal any radiation damage. The bioXTAS RAW ${ }^{48}$ software was used for radial averaging and background subtraction. The average molecular mass of the protein was estimated from the extrapolated forward scattering $\mathrm{I}(0)$ by using a reference solution of bovine serum albumin. The molecular weights from $\mathrm{I}(0)$ and the radii of gyration were determined from the Guinier approximation using PRIMUS.
\end{abstract}

Synchrotron radiation circular dichroism (SRCD). SRCD spectra were collected on the AUCD beamline at the ASTRID synchroton radiation source (Institute for Storage Ring Facilities, University of Aarhus, Denmark). The light from the AU-CD beam line was polarized with a MgF2 Rochon polarizer (B-Halle GmbH, Berlin) and a photo elastic modulator (Hinds, USA) produced alternating left and right handed circular polarized light. The light was then passed though the protein sample $(1 \mathrm{mg} / \mathrm{mL})$ and was detected by a photo multiplier tube (Type 9406B, ETL, UK). Camphor-sulfonic acid served as a calibration material for the instrument. Samples were loaded in a quartz cuvette (121.000 QS, $1 \mathrm{~mm}$ path, Hellma Analytics) and data were collected in the range $170-280 \mathrm{~nm}$ with a 1-nm step. High transmission voltage (HV) was also monitored. Measurements on buffers and protein samples were performed in duplicate and 
triplicate, respectively. Spectra were then averaged and smoothed with a Savitzky-Golay filter. Buffer-subtracted spectra of protein samples were normalized by the protein concentration.

\section{Results and Discussion}

Physico-chemical and structural properties of spherulites. We base our work on the hypothesis that changing protein-protein interactions (PPIs) could lead to final aggregate structures with different properties. Co-solvents are traditionally used to modify in vitro PPIs. Specifically, alcohols affect protein hydration shell and protein-solvent interactions, leading to change in electrostatic and hydrophobic interactions. ${ }^{34-42}$ With this idea in mind, we induce human insulin (HI) spherulite formation (see Materials and Methods) both in absence (hereafter called $0 \%$ $\mathrm{EtOH}$ ) and in presence of $40 \% \mathrm{v} / \mathrm{v}$ EtOH (hereafter called $40 \% \mathrm{EtOH})$. Spherulite formation is first verified by cross-polarized microscopy (Figure S1 in supplementary information, SI). ${ }^{17}$

For the 2-photon excitation (2PM) and confocal microscopy (CM) analysis, we stain the two spherulites samples by 1) the amyloid-sensitive dye Thioflavin $\mathrm{T}$ (ThT, green) and the hydrophilic probe Alexa 647 (red) in a double channel configuration (CM, Figure 1a-c and 1e-g), and 2) the hydrophobic dye 8-anilino-1-naphthalene-sulfonate (ANS) (2PM, Figure 1d and 1h). ${ }^{49}$ Both $0 \% \mathrm{EtOH}$ and $40 \% \mathrm{EtOH}$ spherulites are ThT-positive indicating that their molecular structure is stabilized by intermolecular $\beta$-sheet arrangement. ${ }^{49}$ In both samples, ANS fluorescence is fairly uniform within the whole structure indicating a homogeneous distribution of hydrophobic regions. Moreover, morphological differences are clear: in absence of EtOH a radial distribution of elongated aggregates from the central region is detectable (Figure 1d), while $40 \%$ EtOH spherulites are compact with elongated structures hardly distinguishable (Figure 1h). 


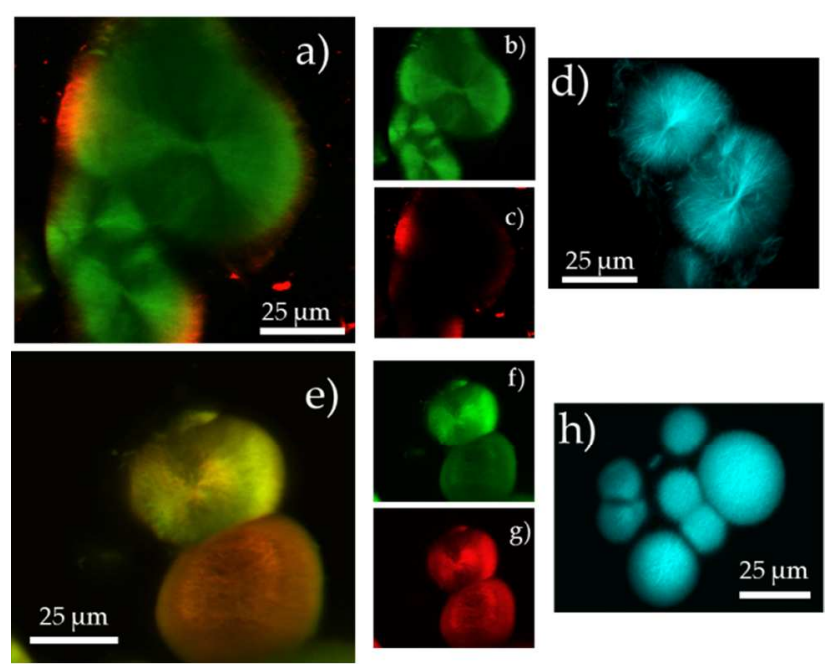

Figure 1 EtOH controls the morphology and physico-chemical properties of spherulites. Fluorescence images of spherulites obtained from human insulin at $5 \mathrm{mg} / \mathrm{ml}$ in acidic solution $0.25 \mathrm{M} \mathrm{NaCl}, \mathrm{pH} 1.8$ incubated at $60^{\circ} \mathrm{C}$ for $24 \mathrm{~h}$. a-d) in absence of EtOH (0\% EtOH) and e-h) in presence of $40 \%$ EtOH. Samples were stained with ThT (green, amyloid-sensitive), Alexa 647 (red, hydrophilicity) and ANS (cyan, hydrophobicity). Images are acquired in double colour configuration (ThT+Alexa 647, a-c- and e-g) and single colour (ANS, d and h). Single channels for ThT and Alexa 647 are also presented (b, c, f and g). In absence of EtOH mainly hydrophobic dyes are hosted in the spherulites, while at $40 \% \mathrm{EtOH}$, both hydrophilic and hydrophobic dyes are able to diffuse within the protein superstructure.

We interestingly detect another significant difference between the two samples. In the conditions used, the hydrophilic dye Alexa $647^{49}$ does not significantly diffuse into the inner part of the $0 \%$ EtOH spherulites in the time scale of several hours (Figure 1c and S2). On the contrary, Alexa 647 readily diffuses into 40\% EtOH spherulites (Figure S2 in SI), being uniformly distributed in the aggregates (Figure 1g) and co-localized with ThT (Figure 1e). This may be related to a different solvent accessibility of the two structures as Alexa 647 is not supposed to have specific interactions with the aggregates. ${ }^{49}$ We can indirectly infer that solvent diffusion is the driving force for its diffusion into spherulites.

If solvent content/accessibility is different in the two samples, one should expect the two structures to have different responses to a dehydration procedure. We dehydrate the samples and 
analyze them using Atomic Force Microscopy (AFM). In the case of $0 \%$ EtOH spherulites, the surface shows a significant roughness (Figure 2a and c). Moreover, as expected ${ }^{50}$ spherulites coexist with a minor fraction of elongated fibril-like structures (Figure 2b and Figure S3 in SI). On the contrary, for $40 \% \mathrm{EtOH}$ spherulites after dehydration, we observe a collapse of the spherical structure. Near the center of the spherulites a surface with a vanishing roughness is observed (Figure 2d). At the spherulite edge a series of well-defined overlapping planes reveals an almost crystalline arrangement of the protein molecules after dehydration (Figure 2e).

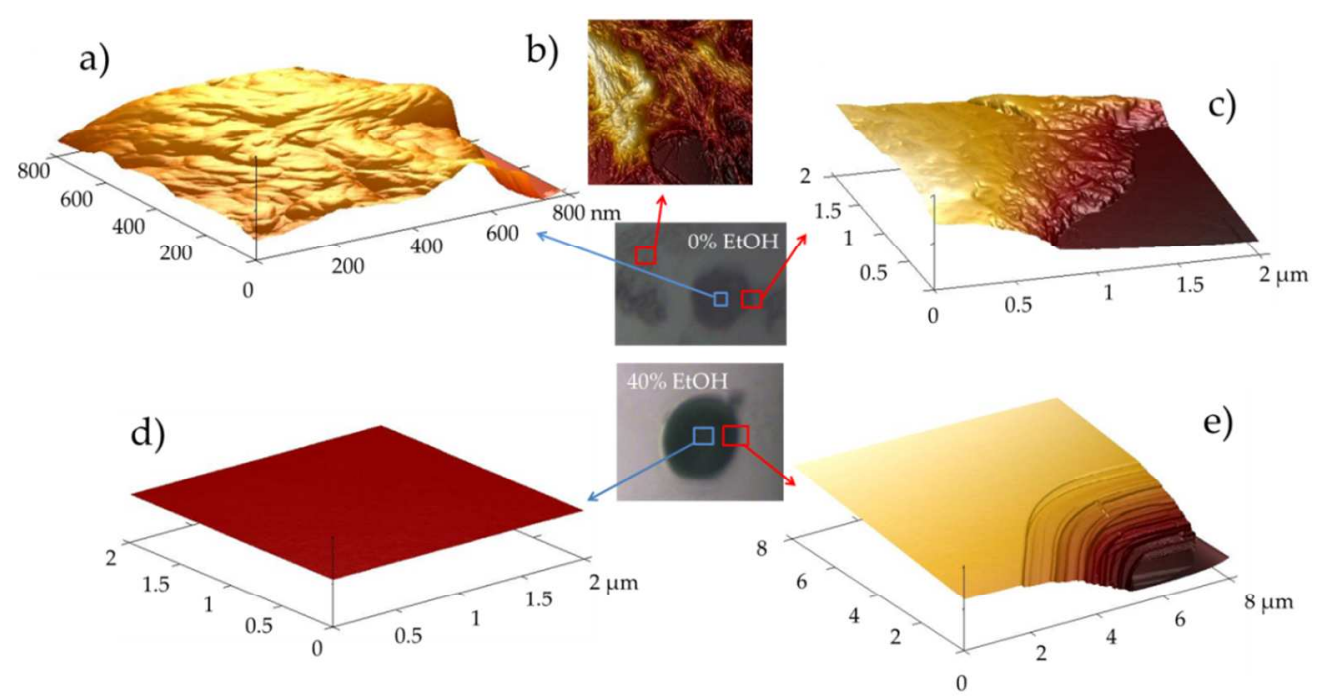

Figure 2 EtOH modifies the microscopic structure of spherulites. Representative Atomic Force Microscopy (AFM) measurements of spherulites formed (a and c) in absence and (d and e) presence of $40 \% \mathrm{v} / \mathrm{v}$ EtOH. In b) fibrils formed in absence of EtOH are shown. Optical microscopy images of the spherulites are shown to indicate the spherulite areas investigated by AFM. Z-ranges are: a) and d) $\sim 760 \mathrm{~nm}, \mathrm{c}) \sim 2 \mu \mathrm{m}$, and e) $\sim 6.6 \mu \mathrm{m}$. Water molecules play a crucial role in the morphology of the $40 \% \mathrm{EtOH}$ spherulites, while $0 \% \mathrm{EtOH}$ spherulites are capable of maintaining their structures even after de-hydration.

Moreover, fibrils are not detected using AFM and TEM. The Young modulus for both samples is also obtained by force measurements (see Materials and Methods). For 40\% EtOH spherulites, a value of $\sim 400 \mathrm{MPa}$ is obtained, while $0 \% \mathrm{EtOH}$ samples are barely deformable within the setup used, suggesting a Young modulus $>2 \mathrm{GPa}$. 
Data in Figures 1 and 2 reveal the critical role of $\mathrm{EtOH}$ in affecting the spherulite properties. It is indeed possible to switch from the formation of a hard species with a hydrophobic interior that preferably excludes water $(0 \% \mathrm{EtOH}$ spherulites), to a deformable species whose water-rich interior, possibly less dense, is able to host both hydrophobic (ANS) and hydrophilic (ALEXA 647) molecules (40\% EtOH spherulites). Moreover, once the solvent is removed a collapse of the structure occurs for $40 \% \mathrm{EtOH}$ spherulites. We cannot rule out that a similar effect is also present in the $0 \% \mathrm{EtOH}$ sample but, if any, this takes place to a very minor extent.

Mechanical properties of spherulites. Morphological and mechanical properties are dependent on the structure. To rationalize this connection we analyze pressure-induced modifications in spherulite molecular structures by means of FTIR microscopy. We progressively compress both samples from 1 bar to $12 \mathrm{kbar}$ (see Materials and Methods) and acquire IR single-spherulite absorption spectra. This allows us to simultaneously probe the molecular structure and the response to mechanical stress. We focus on the Amide I' band $\left(1580-1710 \mathrm{~cm}^{-1}\right.$, Figure $3 \mathrm{a}$ and b) as a probe for protein secondary structures. At ambient pressure, a broad peak at $1620 \mathrm{~cm}^{-1}$ (i.e. intermolecular $\beta$-sheets) is present in both samples together with a large peak at 1660-1680 $\mathrm{cm}^{-1}$ (i.e. native-like structures and disordered structures). ${ }^{51,}{ }^{52}$ This last contribution is more pronounced in the $40 \% \mathrm{EtOH}$ sample, highlighting differences in the secondary structure between the two samples.

At 12 kbar (blue lines) changes in the Amide I' shape are observed. The change of the IR signal can be due to i) structural changes of the protein within the aggregate (band shape) or ii) macroscopic modifications of the aggregate (overall band intensity), i.e. flattening of the aggregate with a decrease of protein content through the optical path. In both samples we 

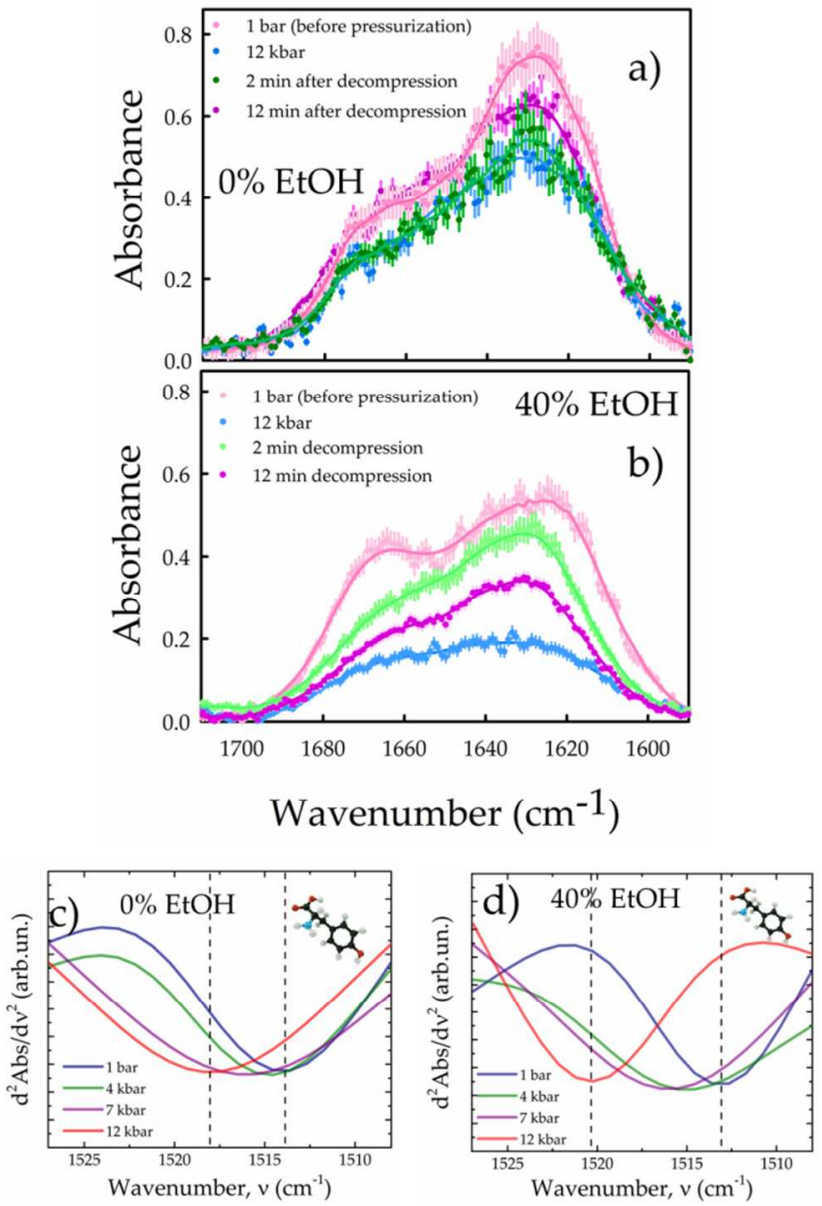

Figure $3 \mathrm{EtOH}$ induces the formation of highly deformable spherulites. HP-FTIR experiments on (a and c) 0\% EtOH spherulites and (b and d) 40\% EtOH spherulites. Spectra are acquired at constant pressures of 1 bar and $12 \mathrm{kbar}$. After reaching $12 \mathrm{kbar}$, samples were suddenly brought to 1 bar. Spectra after decompression to 1 bar (2 and $12 \mathrm{~min})$ are reported (a and b). 2ndderivative spectra of Tyr breathing mode at $1515 \mathrm{~cm}^{-1}$ during the compression cycle (from 1 bar to $12 \mathrm{kbar}$ ) for $0 \% \mathrm{EtOH}$ (c) and $40 \% \mathrm{EtOH}(\mathrm{d})$. High pressure experiments show that the $40 \%$ EtOH spherulites are highly deformable compared to the ones formed in absence of EtOH.

observe both a reduction of the ratio between the $1620 \mathrm{~cm}^{-1}$ and the $1660-1680 \mathrm{~cm}^{-1}$ peaks, in accordance with a report on insulin fibrils, ${ }^{52}$ and an overall reduction of the band intensity. These changes are more pronounced in the sample at $40 \%$ EtOH. As discussed above, spherulites in both samples are mainly stabilized by intermolecular $\beta$-sheets, but differ in the content of nativelike and disordered structures (Figure $3 \mathrm{a}$ and $3 \mathrm{~b}$, pink data sets). When the latter is more pronounced $(40 \% \mathrm{EtOH})$ spherulites are more deformable. This can be due to differences in the 
stability of the secondary structures upon pressure. To address this key point, we proceed as follows: we monitor the Amide I' spectra at different times after sudden pressure release from 12 kbar to 1 bar. Spectra at 2 (green) and 12 minutes (magenta) after the pressure release are shown in Figures $3 \mathrm{a}$ and $\mathrm{b}$. No further changes occur after 12 minutes. Upon decompression, in the sample at $0 \% \mathrm{EtOH}$, the signal at $1660 \mathrm{~cm}^{-1}$ goes back to its initial state, while the intensity at $1620 \mathrm{~cm}^{-1}$ is reduced of $\sim 20 \%$ compared to the untreated sample. This suggests a loss of intermolecular H-bonds stabilizing the spherulites. ${ }^{53}$ Interestingly, 2 minutes after decompression (green), the Amide I' band intensity of $40 \% \mathrm{EtOH}$ sample increases to a higher value than the one reached at equilibrium (12 minutes, magenta). This indicates a significant elastic response of the $40 \% \mathrm{EtOH}$ spherulites as a whole. However, for $40 \% \mathrm{EtOH}$ spherulites, the content of native-like and disordered structures decreases compared to the untreated sample together with a reduction of lower number components of $1620 \mathrm{~cm}^{-1}$ peak, attributed to stronger H-Bonds (or longer $\mathrm{H}$ bonds chains). ${ }^{51,52,54,55}$ This proves that an irreversible and significant change in the secondary structure is associated to the high degree of deformability of the $40 \% \mathrm{EtOH}$ spherulites. Interestingly, and in line with our results, structural differences between insulin amyloid fibrils grown in presence of EtOD compared to fibrils grown in $\mathrm{D}_{2} \mathrm{O}$ are reported ${ }^{36}$. EtOD is suggested to probably affect the packing mode of protein molecules into fibrils ${ }^{36}$ and, as a consequence, their stability. Our data highlight that EtOH-induced structural differences can also arise in large scale arrangements as spherulites; this indicates a potential general effect of EtOH in modulating the whole range of protein aggregate structures.

Our data points towards the hydration states of protein structures as determining structural and mechanical properties of the spherulites. To prove this we monitor the hydration state and compactness of the structure during the pressurization cycle through the position of the 
Tyrosine (Tyr) ring breathing mode (i.e. minimum in the second derivative of the IR signal around $\left.1515 \mathrm{~cm}^{-1}\right){ }^{52,55-58}$ Upon pressurization ( 1 bar to $12 \mathrm{kbar}$ ), in the $0 \% \mathrm{EtOH}$ sample (Figure $3 \mathrm{c}$ from blue to red line) we observe a shift of this vibrational mode of $\sim 3 \mathrm{~cm}^{-1}$ to higher wavenumbers (comparable to the one reported for fibrils ${ }^{52}$ ); a larger shift of $\sim 8 \mathrm{~cm}^{-1}$ is observed for the $40 \%$ EtOH sample (Figure $3 \mathrm{~d}$ from blue to red line). A larger shift of this peak to higher frequencies can be interpreted as an enhanced level of hydration of the Tyr environment. ${ }^{58}$ This means that $40 \% \mathrm{EtOH}$ spherulites are capable of absorbing a greater number of water molecules compared to the $0 \%$ EtOH, e.g. a larger compressibility for the $40 \%$ EtOH spherulites. ${ }^{57}$

Ethanol controls spherulite growth and properties. We now want to address the following questions: is it possible to relate the differences in the physico-chemical properties of the aggregates to the intra and inter-protein interactions taking place in the two systems? And, ultimately, is it possible to achieve a rational control over the growth and properties of spherulites? To answer these questions we analyze the initial protein conformation/state and the self-assembly kinetics for both samples.

Figure 4 presents the characterization of the two initial states $(0 \% \mathrm{EtOH}$ and $40 \% \mathrm{EtOH})$ prior aggregation using Small Angle X-ray Scattering (SAXS, Figure 4a and 4b, see Materials and Methods for details on the SAXS analysis) and Synchrotron Radiation Circular Dichroism (SRCD, Figure 4c). From a Guinier analysis of the SAXS data (using PRIMUS) ${ }^{59}$ we obtain species with a MW of approximately $20.7 \mathrm{kDa}(0 \% \mathrm{EtOH})$ and $\sim 7 \mathrm{kDa}(40 \% \mathrm{EtOH})$. This suggests species formed by an average of 3-4 insulin monomers for the $0 \% \mathrm{EtOH}$ sample and an almost monomeric solution for the $40 \% \mathrm{EtOH}$ sample. This is in agreement with the formation of low molecular weight 

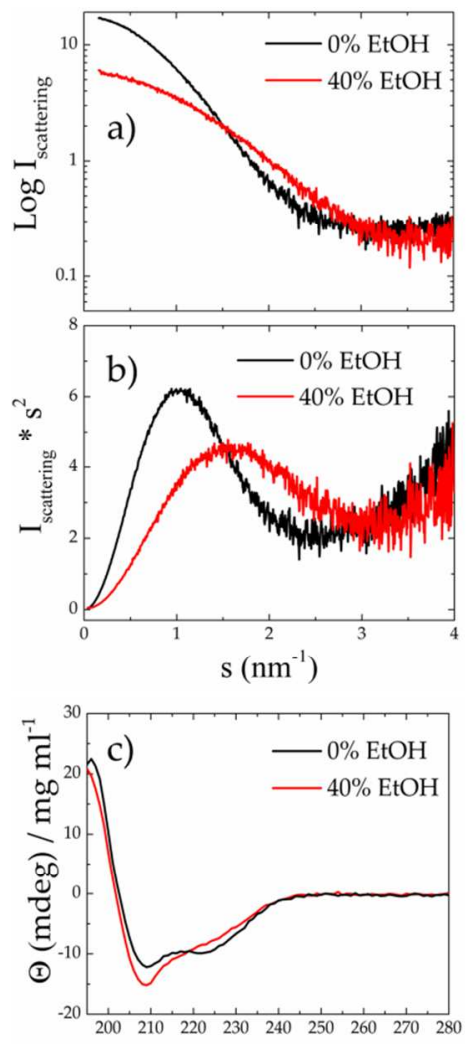

Wavelength $(\mathrm{nm})$ d)

EtOH $0 \%$

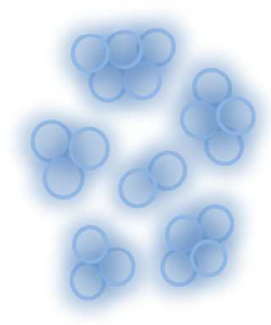

Hydration layer
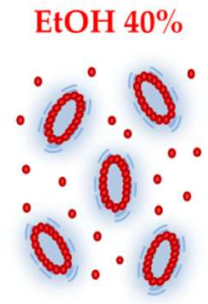

Structured water around protein-bounded EtOH molecules

Figure 4 Human insulin $5 \mathrm{mg} / \mathrm{ml}$ in acidic solution $0.25 \mathrm{M} \mathrm{NaCl}, \mathrm{pH} 1.8$ at $0 \%$ and $40 \% \mathrm{EtOH}$ prior incubation. Small Angle X-ray scattering intensity (a) and Krakty plot (b). c) Far-UV Circular Dichroism spectra. d) Representative scheme of the results from panel a-c. A mixture of compact and folded oligomers with an overall average MW corresponding to trimers-tetramers with hydration layer (light blue edges) occurs in absence of $\mathrm{EtOH}$, while flexible monomers with a double layer of preferentially bounded EtOH molecules (red circles) and structured water (dashed blue lines) are mainly present in solutions at $40 \% \mathrm{EtOH}$.

species of insulin at low pHs. ${ }^{60}$ Measurements at lower concentrations reveal a concentrationdependent oligomerisation at 0\% EtOH (see Table S1 in SI). Moreover, as evident by the bell shape curve in the Kratky plot (Figure $4 \mathrm{~b}$, see the $\mathrm{s}<2 \mathrm{~nm}^{-1}$ range), $0 \%$ EtOH species are mainly folded. ${ }^{49}$ This characteristic shape is partially lost for the $40 \%$ EtOH samples, indicating a less folded and less compact structure. ${ }^{49}$ SRCD far-UV spectra in Figure 4c show well-defined minima at 208 and $222 \mathrm{~nm}$ that indicate the main presence of $\alpha$-helical structures for $0 \% \mathrm{EtOH}^{36}$ For $40 \% \mathrm{EtOH}$, the increasingly negative Cotton effect at $208 \mathrm{~nm}$ and the simultaneous decay of 
ellipticity at $222 \mathrm{~nm}$ (Figure 4c) suggest that EtOH induces a more disordered structure retaining a helical content. ${ }^{36}$

In a mixture with water, EtOH can decrease the dielectric constant of the solvent and the Debye screening. ${ }^{36,37}$ Depending on the concentration, EtOH preferentially binds to the proteins (Figure $4 \mathrm{~d}$, red circles) and interacts with water via H-bonding. ${ }^{37,38}$ This modifies the protein hydration layer in a concentration-dependent manner. These effects on protein molecules and solvent have as a final result an increase in the repulsion between molecules. This can explain the opposite tendency towards association observed in the two systems (Figure 4a and Table S1): when EtOH is present, the enhanced repulsion between the protein molecules prevents any oligomerization before inducing spherulite formation. This suggests a strong intermolecular protein-protein repulsion in the presence of EtOH. ${ }^{36}$ Results in Figure 4 a-c are summarized in the representative scheme in Figure 4d.

Data in Figures 1-4 create a link between the features of initial states and final aggregates. The last step for achieving a rational control over the growth of such structures is to directly connect the PPIs (Figure 4) and the properties (Figures 1-3) to the growth of the spherulites. We then analyze the aggregate kinetics to have details on PPIs. ${ }^{27}$ We monitor the spherulite growth using Thioflavin T (ThT). HI is dissolved in water-EtOH mixtures in which EtOH is preferentially bound to the protein $(>20 \% \mathrm{v} / \mathrm{v})^{36}$ and up to $40 \%$ EtOH concentration. In agreement with a previous report ${ }^{36}$, a delay of the aggregation process is observed at increasing concentration of EtOH (Figure 5a). In order to achieve a quantitative connection between PPIs and the properties of spherulites we develop a model for kinetics analysis that explicitly considers the interaction potentials (full description of the model in the SI). We use the following analytical formula to fit the kinetics: 


$$
I(t) \propto \frac{-2+\left(\frac{t}{t+\theta}\right)^{k_{m}}\left[2+k_{m} \log \left(\frac{t}{t+\theta}\right)\left(-2+k_{m} \log \left(\frac{t}{t+\theta}\right)\right)\right]}{3\left(-1+\left(\frac{t}{t+\theta}\right)^{k_{m}}\right) \log \left(\frac{t}{t+\theta}\right)^{2}}
$$

The parameter $\theta=2 /\left(k_{+} c_{0}\right)$ represents the characteristic time-scale of aggregation, and contains the aggregation rate $k_{+}=k_{S} / W$, where $k_{S}=(8 / 3) k_{B} T / \mu$ is the diffusion-limited aggregation rate (independent of protein-protein potential), $W=2 a \int_{0}^{\infty} \frac{\exp \left(V / k_{B} T\right)}{(2 a+h)^{2} G(h)} d h$ is the Fuchs' stability ratio which contains the protein-protein potential $V$ explicitly and $c_{0}$ is the initial concentration of monomers. $k_{\max }$ is the maximum size that the aggregates can reach and $G(h)$ represents the hydrodynamic interaction between two spheres. We model $V$ using i) an electrostatic doublelayer repulsion, because the proteins are charged; ii) an attraction term encompassing van der Waals and hydrophobic attractions (please see SI and ref. 27) and iii) hydration repulsion due to water and EtOH structuring in between the two proteins or next to their interfaces with water (please see SI).
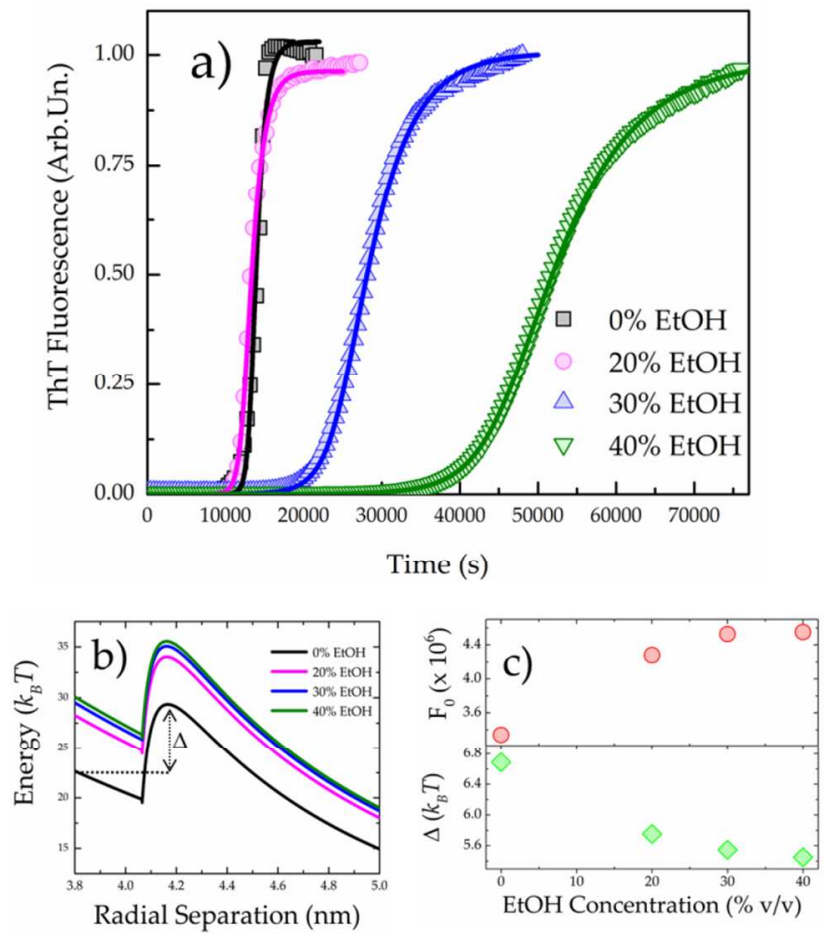
Figure $5 \mathrm{EtOH}$ controls both the growth and properties of spherulites. ThT fluorescence kinetics for human insulin samples at $5 \mathrm{mg} / \mathrm{ml}$ in acidic solution $0.25 \mathrm{M} \mathrm{NaCl}, \mathrm{pH} 1.8$ during incubation at $60^{\circ} \mathrm{C}$ and in different water-EtOH mixtures. Experimental data (symbols) and fitting obtained using Eq. 1 (solid lines). b) Potential energy for protein-protein interactions as obtained by the theoretical model (see text and SI). $\Delta$ is the binding energy between two proteins within the spherulites. $\Delta$ is shown for the sample $0 \% \mathrm{EtOH}$ as an example. c) Strength of the repulsion $\mathrm{F}_{0}$ between two protein molecules as obtained from the fitting (red circles) and binding energy $\Delta$ (green diamond) as a function of the $\mathrm{EtOH}$ concentration. Increasing the $\mathrm{EtOH}$ concentrations leads to: 1) an increased protein-protein repulsion and 2) a decrease in the binding energy between two proteins within the spherulites. The latter effect leads to more deformable structures at high EtOH concentrations.

We estimate contributions i) and ii) using the same parameters as reported in our earlier work. ${ }^{27}$ For the hydration repulsion we used the standard exponentially-decaying repulsive force $V_{\text {hydr }}=\pi F_{0} a \lambda^{2} \exp [-\beta(r-2 a) / \lambda]$, where $\beta=1 / k_{B} T, a$ is the radius of the molecule and $\lambda$ is the range of the repulsion, which is related to the thickness of highly-structured water molecules in the gap between two proteins. ${ }^{37,61}$ Different concentrations of EtOH lead to differences in the arrangement of the hydration layer, modifying the repulsive contribution $V_{h y d r}$. This potential has two parameters, the range $\lambda$ and the strength of the repulsion $F_{0}$. For the range we choose the typical thickness of $\sim 10$ water molecules, giving $\lambda=2 \mathrm{~nm}^{27,} 37$ This typical value of the repulsion range is not very sensitive to the chemical composition of the system, ${ }^{37}$ therefore we keep it constant in the fitting upon varying the EtOH concentration. The strength of the repulsion $F_{0}$ can vary depending on the chemical composition. We leave it as a fitting parameter, varying it within the typical range of values reported in the literature. ${ }^{37}$

The average unfolding time $\bar{\tau}$ and its variance $s$ are also fitting parameters but they play no role in the part of the sigmoid solely controlled by aggregation. Using $F_{0}$ as the unique fitting parameter for $k_{+}$we perform the numerical simulations that show a good match with the data (solid lines in Figure 5a). From the fitting we extract the total protein-protein interaction 
potentials as a function of EtOH concentration (Figure $5 \mathrm{~b}$ ) and the parameter $F_{0}$ (Figure $5 \mathrm{c}$, red circles). There is a significant increase in the effective protein-protein hydration repulsion strength $F_{0}$ at increasing EtOH concentrations. This corroborates our data in Figure 4. Moreover, the hydration repulsion contribution has another interesting effect: it "lifts up" the attractive well. This is related to the mechanical properties of the spherulites. The main consequence of this liftup of the minimum is indeed that the effective binding energy between two proteins within a spherulite decreases. We estimate the binding energy as the difference between the energy of the barrier top and the highest energy in the well, $V_{\text {barrier }}-V_{\text {well }} \equiv \Delta$ (Figure $5 \mathrm{~b}$ ). We obtain a decreasing binding energy at increasing EtOH concentrations (Figure 5c, green diamonds) with values of $6.80 \mathrm{k}_{\mathrm{B}} \mathrm{T}$ and $5.47 \mathrm{k}_{\mathrm{B}} \mathrm{T}$ for the sample at $0 \%$ and $40 \%$, respectively. For a finite compression of the material, the binding energy values are proportional to the bulk modulus ${ }^{62}$ giving information on the aggregate resistance to uniform compression. This means that the spherulites formed at $0 \% \mathrm{EtOH}$ are more resistant to mechanical deformation than the $40 \%$ EtOH samples, theoretically validating the experimental data as obtained by AFM and IR spectroscopy.

\section{Conclusions}

In summary we have provided experimental evidence of a key role of hydration layer and solvent properties in determining the self-assembly mechanism, structure and properties of amyloid-like spherulites. Spherulites can indeed host hydrophobic and/or hydrophilic molecules, change their morphology and mechanical properties in response to a change in the solvent properties and hydration shell of the single protein molecules. We highlight the possibility for spherulites to simultaneously load molecules with different features, which is the key property in the development of systems for co-delivery of drugs. ${ }^{63,64} \mathrm{We}$ also prove the ability for spherulites 
to span a wide range of elastic modulus values from few hundreds of MPa typical of native protein crystals ${ }^{65}$ to several GPa often observed for collagen. ${ }^{66}$ All the above experimental observations are validated by a theoretical model able to predict the spherulites growth and properties as a function of the protein hydration state.

The implications of our results are two-fold. On one hand, our findings promote structural polymorphism as a general phenomenon for the entire range of amyloid-like aggregates and not limited to fibrils. Structural polymorphism of amyloid fibrils can determine the development of neurodegenerative protein-related diseases, ${ }^{23}$ and its origin is often considered dependent on the protein sequence ${ }^{67}$ and environmental conditions. ${ }^{68}$ We here identify hydration as a driving force for the determination of specific packing of insulin molecules into spherulites. We also show that a modified hydration of the single protein molecule leads to a self-assembling into spherulites with different morphologies and physico-chemical properties. Due to the role of spherulites in Alzheimer's disease ${ }^{21,22}$ this polymorphism can, as for fibrils, ${ }^{23}$ lead to different biological effects, and our results highlight the role of fundamental PPIs and protein environment in selecting specific structures among the wide range of accessible species. Despite its medical implication, our work contributes to the establishment of a generalized energy landscape for proteins that includes self-assembly. ${ }^{69,70}$ Indeed, the existence of species (other than fibrils) that show a structural variability translates into the appearance of new energy minima in the multidimensional protein energy landscape, providing a more accurate picture of the conformational states available for a protein. ${ }^{69,70}$

On the other hand, our results give further insights on the main role of water in defining mechanical properties of self-assembled structures. Altering the liquid environment after the production of protein-based fibrils can modulate their mechanical properties. ${ }^{71}$ Here we show 
that tuning the elastic properties can also be reached by modulating the protein hydration and solvent properties during the material growth. In this perspective, we provide a flexible and broad framework for the rational design of highly-tunable protein 3D biomaterials using bottomup approaches. Indeed, achieving a fine control of the physico-chemical interactions between proteins is of interest for designing self-assembled biomaterials in areas such as bio-sensing, ${ }^{72}$ and nano-medicine. ${ }^{73}$ One could foresee the possibility to modify not only the hydration forces, but also the entire range of different PPIs. This can allow one to explore an uncountable variety of material properties. This approach could represent a powerful alternative to chemical modifications, ${ }^{8,11,74}$ opening new scenarios in the design of advanced protein materials.

\section{ASSOCIATED CONTENT}

Supporting Information. Details on the theoretical model as well as supplementary data are reported in supplementary information. This material is available free of charge via the Internet at http://pubs.acs.org

\section{AUTHOR INFORMATION}

\section{Corresponding Author}

*vito.fodera@sund.ku.dk (VF)

\section{Author Contributions}

V.F. designed the research project and was responsible for work concept, planning and management. A.Z. developed the theoretical model. A.Z. and J.K. performed the numerical simulations. F.P. and V.F. performed the HP-FTIR experiments. F.P. and V.V. performed the HP-FTIR data analysis. V.V. and V.F. performed the microscopy experiments. B.V. and V.F. 
performed the SAXS experiments and analysis. V.F. performed the fluorescence and CD experiments. G.B. and V.V. performed the AFM experiments and analysis. U.L. performed the cross-polarized optical microscopy experiments. V.F. wrote the manuscript together with V.V., F.P., B.V. and A.Z. All authors agree on the data interpretation and contribute to the drafting of the manuscript.

\section{ACKNOWLEDGMENTS}

V.F. acknowledges support from the FP7 Marie-Curie Actions Intra European Fellowship (IEF) for Career Development 2012-2014, project nr. 299385 "FibCat" (University of Copenhagen). BV is thankful for funding from the Danish Council for Independent Research, Medical Sciences Sapere Aude project SAFIR, and for financial support from DANSCATT for data collections. Dr. Paul Dumas, Dr. Christophe Sandt and Dr. Ferenc Borondics are acknowledged for the support during the HP-FTIR experiments at the SMIS beamline, in SOLEIL (Paris, France). Fluorescence microscopy measurements were performed at "Microscopy and Bio-imaging Lab" at the Mediterranean Center for Human Health Advanced Biotechnologies (CHAB), University of Palermo. We acknowledge the Core Facility for Integrated Microscopy, Faculty of Health and Medical Sciences, University of Copenhagen for access to performing the Transmission Electron Microscopy experiments. 


\section{REFERENCES}

[1] Knowles, T.P.J.; Vendruscolo, M.; Dobson, C.M. The amyloid state and its association with protein misfolding diseases. Nat Rev Mol Cell Biol. 2014, 15, 384-396.

[2] Campioni, S.; Mannini, B.; Zampagni, M.; Pensalfini, A.; Parrini, C.; Evangelisti, E.; Relini, A.; Stefani, M.; Dobson, C.M.; Cecchi, C.; Chiti, F. A causative link between the structure of aberrant protein oligomers and their toxicity. Nature Chemical Biology 2010, 6, 140-147.

[3] Sawaya, M.R.; Sambashivan, S.; Nelson, R.; Ivanova, M.I.; Sievers, S.A.; Apostol, M.I.; Thompson, M.J.; Balbirnie, M.; Wiltzius, J.J.; McFarlane, H.T.; Madsen, A.Ø.; Riekel, C.; Eisenberg, D. Atomic structures of amyloid cross-beta spines reveal varied steric zippers. Nature 2007, 447, 453-457.

[4] Kotler, S.A.; Walsh, P.; Brender, J.R.; Ramamoorthy, A. Differences Between AmyloidAggregation in Solution and on the Membrane: Insights into Elucidation of the Mechanistic Setails of Alzheimer's Disease. Chem. Soc. Rev. 2014, 43, 66926700.

[5] Mankar, S.; Anoop, A.; Sen, S.; Maji, S.K. Nanomaterials: amyloids reflect their brighter side. Nano Rev. 2011 2, 6032.

[6] Knowles, T.P.J.; Buehler, M.J. Nanomechanics of functional and pathological amyloid materials Nature Nanotechnology 2011, 6, 469-479.

[7] Knowles, T.P.J.; Mezzenga R. Amyloid Fibrils as Building Blocks for Natural and Artificial Functional Materials Adv Mater. 2016, 28, 6546-6561.

[8] Webber, M.J.; Appel, E.A.; Meijer, E.W.; Langer, R.; Supramolecular biomaterials Nature Materials 2015, 15, 13-26. 
[9] Kumar, S.T.; Meinhardt, J.; Fuchs, A.K.; Aumüller, T.; Leppert, J.; Büchele, B.; Knüpfer, U.; Ramachandran, R.; Yadav, J.K.; Prell, E.; Morgado, I.; Ohlenschläger, O.; Horn, U.; Simmet, T.; Görlach, M.; Fändrich, M. Structure and biomedical applications of amyloid oligomer nanoparticles. ACS Nano, 2014, 8, 11042-11052.

[10] Mart, R.J.; Osborne, R.D.; Stevens, M.M.; Ulijn, R.V. Peptide-based stimuli-responsive biomaterials. Soft Matter, 2006, 2, 822-835.

[11] Langer, R.; Tirrell, D.A. Designing materials for biology and medicine. Nature 2004, 428, 487-492.

[12] Vetri, V.; Foderà, V. The Route to Protein Aggregate Superstructures: Particulates and Amyloid-like Spherulites, FEBS Letters, 2015, 589, 2448-2463.

[13] Seuring, C.; Verasdonck, J.; Ringler, P.; Cadalbert, R.; Stahlberg, H.; Böckmann, A.; Meier, B.H.; Riek, R. Amyloid Fibril Polymorphism: Almost Identical on the Atomic Level, Mesoscopically Very Different. J Phys Chem B. 2017, 121, 1783-1792.

[14] Fändrich, M.; Meinhardt, J.; Grigorieff N. Structural polymorphism of Alzheimer Abeta and other amyloid fibrils. Prion, 2009, 3, 89-93.

[15] Pinotsi, D.; Buell, A.K.; Galvagnion, C.; Dobson, C.M.; Kaminski Schierle, G.S.; Kaminski C.F. Direct observation of heterogeneous amyloid fibril growth kinetics via two-color superresolution microscopy. Nano Lett. 2014, 14, 339-45.

[16] Lin, H.K.; Boatz, J.C.; Krabbendam, I.E.; Kodali, R.; Hou, Z.; Wetzel, R.; Dolga, A.M.; Poirier, M.A.; van der Wel, P.C.A. Fibril polymorphism affects immobilized non-amyloid 
flanking domains of huntingtin exon1 rather than its polyglutamine core. Nat Commun. 2017, 8 , 15462.

[17] Krebs, M.R.H.; MacPhee, C.E.; Miller, A.F.; Dunlop, I.E.; Dobson, C.M.; Donald, A.M. The formation of spherulites by amyloid fibrils of bovine insulin, Proc Natl Acad Sci USA 2004, $101,14420-14424$.

[18] Domike, K.R.; Donald, A.M. Thermal dependence of thermally induced protein spherulite formation and growth: kinetics of $\beta$-lactoglobulin and insulin. Biomacromolecules 2007, 8, 3930-3937.

[19] Bolder, S.G.; Hendrickx, H.; Sagis, L.M.; van der Linden E. Fibril assemblies in aqueous whey protein mixtures. J Agric Food Chem 2006, 54, 4229-4234.

[20] Smith, M.I.; Foderà, V.; Sharp, J.S.; Roberts, C.J.; Donald, A.M. Factors affecting the formation of Insulin Amyloid Spherulites. Colloids and Surfaces B: Biointerfaces 2012, 89, 216222

[21] Exley, C.; House, E.; Collingwood, J.F.; Davidson, M.R.; Cannon, D.; Donald, A.M.; Spherulites of Amyloid-beta(42) In Vitro and in Alzheimer's Disease. J Alzheimers Dis 2010, 20, 1159-1165.

[22] House, E.; Jones, K.; Exley, C. Spherulites in Human Brain Tissue are Composed of Beta Sheets of Amyloid and Resemble Senile Plaques. J Alzheimers Dis. 2011, 25, 43-46.

[23] Tycko R. Amyloid polymorphism: structural basis and neurobiological relevance. Neuron. 2015, $86,632-645$. 
[24] Karamanos, T.K.; Kalverda, A.P.; Thompson, G.S.; Radford, S.E. Visualization of transient protein-protein interactions that promote or inhibit amyloid assembly. Mol Cell. 2014, 55, 214226.

[25] Jannone, J.M.; Grigg, J.I.; Aguirre, L.M.; Jones, E.M. Electrostatic Interactions at N- and CTermini Determine Fibril Polymorphism in Serum Amyloid A Fragments. J Phys Chem B. 2016, $120,10258-10268$.

[26] Chatani, E.; Yagi, H.; Naiki, H.; Goto, Y.; Polymorphism of $\beta 2$-microglobulin amyloid fibrils manifested by ultrasonication-enhanced fibril formation in trifluoroethanol. $J$ Biol Chem. 2012, 287, 22827-22837.

[27] Foderà, V.; Zaccone, A.; Lattuada, M.; Donald A.M. Electrostatics controls the formation of amyloid superstructures in protein aggregation Phys. Rev. Lett. 2013, 111, 108105.

[28] Baldwin, R.L.; Rose, G.D. How the hydrophobic factor drives protein folding. Proc Natl Acad Sci U S A. 2016, 113, 12462-12466.

[29] Cheung, M.S.; García, A.E.; Onuchic, J.N. Protein folding mediated by solvation: water expulsion and formation of the hydrophobic core occur after the structural collapse. Proc Natl Acad Sci U S A. 2002, 99, 685-690.

[30] Silva, J.L.; Foguel, D. Hydration, cavities and volume in protein folding, aggregation and amyloid assembly Phys Biol. 2009, 6, 015002.

[31] Gallat, F.X.; Laganowsky, A.; Wood, K.; Gabel, F.; van Eijck, L.; Wuttke, J.; Moulin, M.; Härtlein, M.; Eisenberg, D.; Colletier, J.P.; Zaccai, G.; Weik, M.; Dynamical coupling of 
intrinsically disordered proteins and their hydration water: comparison with folded soluble and membrane proteins. Biophys J. 2012, 103, 129-136.

[32] Thirumalai, D.; Reddy, G.; Straub; J.E. Role of water in protein aggregation and amyloid polymorphism. Acc Chem Res, 2012, 45, 83-92.

[33] Fichou, Y.; Schirò, G.; Gallat, F.X.; Laguri, C.; Moulin, M.; Combet, J.; Zamponi, M.; Härtlein, M.; Picart, C.; Mossou, E.; Lortat-Jacob, H.; Colletier, J.P.; Tobias, D.J.; Weik, M. Hydration water mobility is enhanced around tau amyloid fibers. Proc Natl Acad Sci U S A. 2015, 112, 6365-6370.

[34] Backlund, F.G.; Solin. N. Tuning the aqueous self-assembly process of insulin by a hydrophobic additive. RSC Advances 2015, 5, 92254-92262

[35] Javid, N.; Vogtt, K.; Krywka, C.; Tolan, M.; Winter, R. Protein-protein interactions in complex cosolvent solutions Chem Phys Chem. 2007, 8, 679-689.

[36] Dzwolak, W.; Grudzielanek, S.; Smirnovas, V.; Ravindra, R.; Nicolini, C.; Jansen, R.; Loksztejn, A.; Porowski, S.; Winter, R. Ethanol-Perturbed Amyloidogenic Self-Assembly of Insulin: Looking for Origins of Amyloid Strains. Biochemistry 2005, 44, 8948-8958.

[37] Israelachvili J. Intermolecular and Surface Forces, Academic Press, Amsterdam, 2011.

[38] Timasheff, SN. Protein-solvent preferential interactions, protein hydration, and the modulation of biochemical reactions by solvent components. Proc. Natl. Acad. Sci. U.S.A. 2002, 99, 9721-9726.

[39] Timasheff, S.N. Protein-solvent interactions and protein conformation Acc. Chem. Res., $1970,3,62-68$ 
[40] Ghosh, R.; Samajdar, R.N.; Bhattacharyya, A.J.; Bagchi, B. Composition dependent multiple structural transformations of myoglobin in aqueous ethanol solution: a combined experimental and theoretical study. J Chem Phys. 2015, 143, 015103

[41] Chattoraj, S.; Mandal, A.K.; Bhattacharyya K. Effect of ethanol-water mixture on the structure and dynamics of lysozyme: a fluorescence correlation spectroscopy study. $J$ Chem Phys. 2014, 140, 115105.

[42] Sirotkin, V.A.; Kuchierskaya, A.A. $\alpha$-Chymotrypsin in water-ethanol mixtures: Effect of preferential interactions Chemical Physics Letters 2017, 689, 156-161

[43] Lakowicz, J.R. Principles of Fluorescence Spectroscopy, Springer 2006;

[44] Stryer L. The interaction of a naphthalene dye with apomyoglobin and apohemoglobin. A fluorescent probe of non-polar binding sites. J. Mol. Biol.1965, 13, 482-495.

[45] Hawe, A.; Sutter, M.; Jiskoot, W. Extrinsic fluorescent dyes as tools for protein characterization. Pharmaceutical Research 2008, 25, 1487-1499.

[46] Biancalana, M.; Koide, S. Molecular mechanism of Thioflavin-T binding to amyloid fibrils. Biochim Biophys Acta. 2010, 1804, 1405-1412

[47] Mao, H.K.; Xu, J.; Bell, P.M. Calibration of the ruby pressure gauge to 800 kbar under quasi-hydrostatic conditions J. Geophys. Res. 1986, 91, 4673-4676.

[48] Nielsen, S.S.; Toft, K.N.; Snakenborg, D.; Jeppesen, M.G.; Jacobsen, J.K.; Vestergaard, B.; Kutter, J.P.; Arleth, L. BioXTAS RAW, a software program for high throughput automated 2D and 1D data reduction and preliminary analysis. Journal of Applied Crystallography 2009, 42, 959-964. 
[49] Foderà, V.; Vetri, V.; Wind, T.S.; Noppe, W.; Cornett, C.; Donald, A.M.; Morozova-Roche L.; Vestergaard, B. Observation of the Early Structural Changes Leading to the Formation of Protein Superstructures. J Phys Chem Lett 2014, 5, 3254-3258.

[50] Foderà, V; Donald, A.M. Tracking the Heterogeneous Distribution of Amyloid Spherulites and their Population Balance with Free Fibrils, The European Physical Journal E-Soft Matter \& Biological Physics, 2010, 33, 273-282.

[51] Dzwolak, W.; Smirnovas, V.; Jansen, R.; Winter, R. Insulin forms amyloid in a straindependent manner: An FT-IR spectroscopic study Protein Sci. 2004, 13, 1927-1932.

[52] Piccirilli, F.; Mangialardo, S.; Postorino, P.; Baldassarre, L; Lupi, S.; Perucchi, A. Sequential dissociation of insulin amyloids probed by high pressure Fourier transform infrared spectroscopy Soft Matter 2012, 8, 11863-11870.

[53] Sharma, P.; Verma, N.; Singh, P.K.; Korpole, S.; Ashish. Characterization of heat induced spherulites of lysozyme reveals new insight on amyloid initiation. Scientific Reports 2016, 6, 22475 .

[54] Roy, S.; Jansen, T.L.C.; Knoester, J. Structural classification of the amide I sites of a $\beta$ hairpin with isotope label 2DIR spectroscopy, Phys. Chem. Chem. Phys. 2010, 12, 9347-9357.

[55] Barth, A. The infrared absorption of amino acid side chains. Progress in Biophysics \& Molecular Biology 2000, 74, 141-173.

[56] Percot, A.; Colomban. P.; Paris, C.; Dinh, H.M.; Wojcieszak, M.; Mauchamp, B. Water dependent structural changes of silk from Bombyx mori gland to fibre as evidenced by Raman and IR spectroscopies Vibrational Spectroscopy 2014, 73, 79-89. 
[57] Panick, G.; Winter, R. Pressure-induced unfolding/refolding of ribonuclease A: static and kinetic Fourier transform infrared spectroscopy study. Biochemistry. 2000, 39, 1862-1869.

[58] Castellano, P.; Vignolo, G.; Farías, R.N.; Arrondo, J.L.; Chehín, R. Molecular View by Fourier Transform Infrared Spectroscopy of the Relationship between Lactocin 705 and Membranes: Speculations on Antimicrobial Mechanism, Appl. Environ. Microbiol. 2007, 73, 415-420.

[59] Konarev, P.V.; Volkov, V.V.; Sokolova, A.V.; Koch, M.H.J.; Svergun, D.I. PRIMUS - a Windows-PC based system for small-angle scattering data analysis. J Appl Cryst. 2003, 36, 1277-1282.

[60] Nielsen, L.; Khurana, R.; Coats, A.; Frokjaer, S.; Brange, J.; Vyas, S.; Uversky, V.N.; Fink, A.L.; Effect of environmental factors on the kinetics of insulin fibril formation: elucidation of the molecular mechanism. Biochemistry, 2001, 40, 6036-6046.

[61] Zaccone, A.; Wu, H.; Lattuada, M.; Morbidelli, M. Charged Molecular Films on Brownian Particles: Structure, Interactions, and Relation to Stability. J. Phys. Chem. B 2008, 112, 67936802.

[62] Zaccone, A.; Lattuada, M.; Wu, H.; Morbidelli, M. Theoretical elastic moduli for disordered packings of interconnected spheres. J. Chem. Phys. 2007, 127, 174512

[63] Kratz, F.; Warnecke, A. Finding the optimal balance: challenges of improving conventional cancer chemotherapy using suitable combinations with nano-sized drug delivery systems. J. Control. Release 2012, 164, 221-235. 
[64] Meng, H.A.; Liong, M.; Xia, T.A.; Li, Z.X.; Ji, Z.X.; Zink, J.I.; Nel, A.E. Engineered design of mesoporous silica nanoparticles to deliver doxorubicin and P-plycoprotein siRNA to overcome drug resistance in a cancer cell line, ACS Nano 2010, 4, 4539

[65] Caylor, C.; Speziale, S.; Kriminski, S.; Duffy, T.; Zha, C.S.; Thorne, R.E. Measuring the elastic properties of protein crystals by brillouin scattering. Journal of Crystal Growth 2001, 232, $498-501$.

[66] Wenger, M.P.; Bozec, L.; Horton, M.A.; Mesquida, P. Mechanical properties of collagen fibrils. Biophys $J$. 2007, 93, 1255-1263.

[67] Elkins, M.R.; Wang, T.; Nick, M.; Jo, H.; Lemmin, T., Prusiner, S.B.; DeGrado, W.F.; Stöhr, J.; Hong, M. Structural Polymorphism of Alzheimer's $\beta$-Amyloid Fibrils as Controlled by an E22 Switch: A Solid-State NMR Study. J Am Chem Soc. 2016, 138, 9840-9852.

[68] Tycko, R. Physical and structural basis for polymorphism in amyloid fibrils. Protein Sci. 2014, 23, 1528-1539.

[69] Jahn, T.R.; Radford, S.E. Folding versus aggregation: polypeptide conformations on competing pathways. Arch Biochem Biophys. 2008, 469, 100-117.

[70] Zheng, W.; Tsai, M.Y.; Chen M.; Wolynes, P.G. Exploring the aggregation free energy landscape of the amyloid- $\beta$ protein (1-40). Proc Natl Acad Sci U S A. 2016, 113, 11835-11840.

[71] Grant, C.A.; Brockwell, D.J.; Radford, S.E.; Thomson, N.H. Tuning the elastic modulus of hydrated collagen fibrils. Biophys J. 2009, 97, 2985-1992.

[72] Li, Y.; Lin, T.; Luo, Y.; Liu, Q.; Xiao, W.; Guo, W.; Lac, D.; Zhang, H.; Feng, C.; Wachsmann-Hogiu, S.; Walton, J.H.; Cherry, S.R.; Rowland, D.J.; Kukis, D.; Pan, C.; Lam, K.S. 
A smart and versatile theranostic nanomedicine platform based on nanoporphyrin. Nature Communications 2014, 5, 4712.

[73] Latza, V.; Guerette, P.A.; Ding, D.; Amini, S.; Kumar, A.; Schmidt, I.; Keating, S.; Oxman, N.; Weaver, J.C.; Fratzl, P.; Miserez, A.; Masic, A. Multi-scale thermal stability of a hard thermoplastic protein-based material. Nature Communications 2015, 6, 8313.

[74] Mitragotri, S.; Lahann, J. Physical approaches to biomaterial design Nature Materials 2009, $8,15-23$ 


\section{TABLE OF CONTENTS}

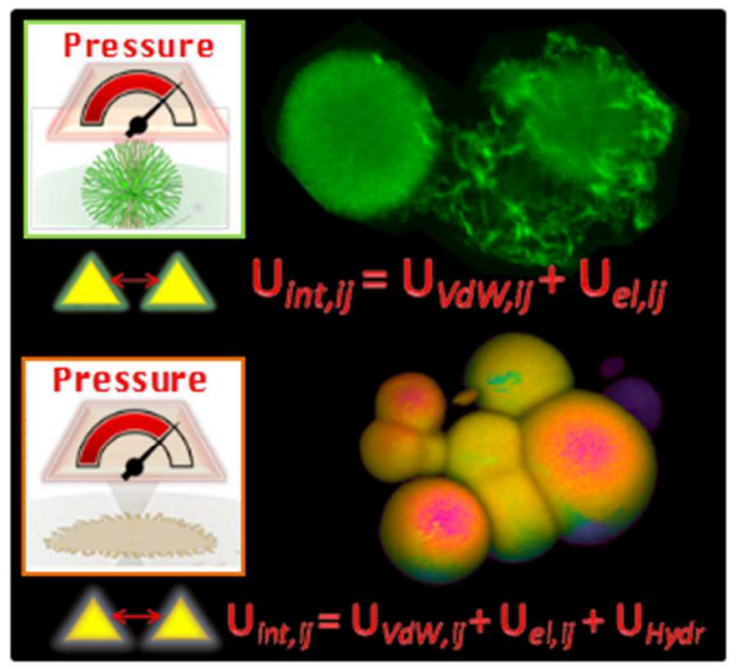

23 